Marquette University

e-Publications@Marquette

Economics Faculty Research and Publications

Economics, Department of

$8-1-2016$

\title{
Is Unemployment Good for the Environment?
}

Andrew G. Meyer

Marquette University, andrew.meyer@marquette.edu

NOTICE: this is the author's version of a work that was accepted for publication in Resource and Energy Economics. Changes resulting from the publishing process, such as peer review, editing, corrections, structural formatting, and other quality control mechanisms may not be reflected in this document. Changes may have been made to this work since it was submitted for publication. A definitive version was subsequently published in Resource and Energy Economics, Vol. 45, (August 2016): 18-30. DOI. (C) 2016 Elsevier. Used with permission. 


\title{
e-Publications@Marquette
}

\section{Economics Faculty Research and Publications/College of Business Administration}

This paper is NOT THE PUBLISHED VERSION; but the author's final, peer-reviewed manuscript. The published version may be accessed by following the link in th citation below.

Resource and Energy Economics, Vol. 45 (August 2016): 18-30. Oㅣ. This article is (C) Elsevier and permission has been granted for this version to appear in e-Publications@Marquette. Elsevier does not grant permission for this article to be further copied/distributed or hosted elsewhere without the express permission from Elsevier.

\section{Is Unemployment Good for the Environment?}

\author{
Andrew Meyer \\ Department of Economics, College of Business, Marquette University, Milwaukee, WI
}

\section{Abstract}

Environmental quality is a public good, potentially impacted by everybody. Individual level pro-environmental behavior affects environmental quality in the aggregate. Therefore, it is important to understand what causes individual's pro-environmental behaviors to change. We quantify the causal effect of one determinant, unemployment, using an EU-27 population representative Eurobarometer survey. Drawing on results from the theory of the private provision of public goods, and recognizing that unemployment decreases income and the opportunity cost of time, we formulate testable predictions that unemployment will decrease the extent of proenvironmental behaviors that require monetary contributions and increase the extent of pro-environmental behaviors that mainly require time/effort. Instrumental variables regressions provide empirical evidence to support these hypotheses. Changes in the unemployment rate within a sub-national region provide the exogenous variation needed to identify the causal effect. Several supplemental questions on the survey provide evidence that environmental issues lose saliency and economic issues gain saliency when one becomes unemployed, suggesting that interested parties may wish to emphasize cost savings of pro-environmental behavior rather than environmental benefits during times of increased unemployment. 


\section{Keywords}

Instrumental variables, Pro-environmental behavior, Eurobarometer survey, Unemployment

\section{Introduction}

Previous studies have examined the determinants of pro-environmental behavior (PEB), mostly focusing on the effects of observable personal characteristics and environmental attitudes. It is important to understand what affects PEB because this can potentially provide insight into which interventions are more likely to encourage behavioral changes. In this paper, we specifically address how unemployment affects PEB. There are several reasons why we may expect unemployment to alter one's extent of PEB. Clark et al. (2003) note that PEB can be viewed as an example of the private provision of a public good. In theoretical models, utility maximizers trade off some private benefit of providing the public good with the private cost. Income is important in these models because it will affect budget and/or time constraints and hence the private cost of contributing to a public good. Income clearly decreases during unemployment, suggesting that PEB may similarly change. Moreover, previous research suggests that behavior may change during unemployment because the opportunity cost of time decreases. For example, Ruhm (2000) finds that unemployment leads to improved health outcomes. Similarly, we may hypothesize that PEB would change with unemployment because of the changing opportunity cost of time.

PEB can manifest in a variety of settings. Some PEB's mainly require time and/or effort as inputs whereas other PEB's require only monetary contributions. Leaning on theoretical findings that income can be important for explaining voluntary contributions to public goods and recognizing that unemployment changes the opportunity cost of time, we formulate testable hypotheses about how unemployment will affect PEB. We predict that behaviors mainly requiring time/effort as inputs will increase with unemployment and behaviors mainly requiring financial contributions as input will decrease with unemployment. We then empirically test these predictions using individual level data on unemployment and PEB.

One empirical challenge is that individual unemployment status may be endogenous in that unemployed individuals may be different from employed individuals in unobservable ways that could affect the extent of their environmental behaviors. Thus, we take a new approach in this paper to address this endogeneity; we instrument for an individual's unemployment status with NUTS-2 1 level regional unemployment to estimate the average causal effect of unemployment status. Our key identifying assumption is that changes in NUTS regional unemployment affect the probability of an individual being unemployed but have no direct effect on an individual's environmental behaviors. 
That is, it is the individual's economic situation that determines their environmental concern and behavior, not the macroeconomic situation that determines one's environmental concern and behavior.

We utilize a representative sample of approximately 30,000 EU-27 individuals to investigate how unemployment affects an individual's extent of PEB. Our main sources of data are two waves (2007 and 2011) of Special Eurobarometer surveys on environmental issues. These surveys provide information on a range of environmental behaviors along with demographics including employment status. Employing NUTS-2 level fixed effects, we exploit variation in unemployment rates within a region over time. Normally, unemployment rates within a region would be quite similar over the span of a few years. However, given the timing of the surveys, the global macroeconomic shocks that took place beginning in 2008 provide a source of exogenous variation in unemployment for the first stage equation.

We find evidence that unemployment impacts the probability that an individual conducts 3 of the 8 possible PEB's 2 on the survey at conventional significance levels. The local average treatment effect is positive and significant for reducing energy usage (0.48-0.77) and reducing car usage (0.35-0.47) and negative and significant for purchasing environmentally labelled products $(-0.21$ to -0.31$)$.

Furthermore, while not statistically significant at conventional levels, we find estimated LATE's that are substantial in magnitude for three other behaviors including reducing disposables ( -0.28 to -0.33$)$, separating waste for recycling (0.08-0.23), and purchasing local products $(-0.30$ to -0.35$)$. On the whole, these results agree with our testable predictions. Furthermore, we find that it is important to address endogeneity because we obtain quite different results when treating individual unemployment as exogenous.

Our stance differs from the Kahn and Kotchen (2011) perspective that a state's unemployment rate affects individuals' relative concern for the environment. They provide evidence of waning environmental concern as unemployment increases by examining google search trends. We note that they examine search data aggregated to the state level so the relationship they document between state level unemployment and environmental concern is also consistent with individual unemployment causing the environmental concern. In a second analysis of climate change survey data, Kahn and Kotchen (2011) do not find a significant relationship between individual unemployment status and probability of reporting concern about climate change. They do, however, find a significant relationship between state level unemployment rates and environmental concern, but only when omitting time dummies. 
Environmental economists have long been concerned with the relationship between economic wellbeing and environmental preferences and behavior. Much of this work relates to aggregate behavior on the macroeconomic level. For example, there is a long line of research on the Environmental Kuznets curve, which postulates an inverse-U-shaped relationship between economic development and environmental protection. The main criticism to this literature is that it has not effectively established a causal link between economic growth and environmental protection. That is, it has not effectively explained the specific factors that may translate increased income into environmental quality (Carson, 2010). Another challenge is that there are alternative explanations for an observed inverse-U-shaped pattern (Andreoni and Levinson, 2001). As such, many economists have concluded that there is little to infer from the EKC literature (Carson, 2010). Yet, it is important for policymakers to understand how economic variables affect environmental behavior.

We are not aware of any other papers that have looked at the causal effect of individual level unemployment on pro-environmental behavior. Several papers have explored the descriptive relationship between unemployment and environmental preferences. For example, Torgler and GarcíaValiñas (2007)examine a wide set of independent variables to explore the determinants of Spanish individuals' environmental attitudes using data from the World Values Survey and European Values Survey. They include employment status in their analysis, but do not find a significant relationship between employment status and environmental attitudes. Torgler et al. (2012) analyze the European Values Survey and find unemployed individuals exhibit a higher probability of stating that littering is justified as compared to full-time employed individuals. Witzke and Urfei (2001) analyze the determinants of willingness to pay for environmental protection, including occupation status. Relative to an individual being employed, only individuals who are engaged in household work have a significantly different willingness to pay. Veisten et al. (2004) find some evidence that individual unemployment is correlated with lower willingness to pay for environmental amenities. However, none of the aforementioned treat occupational status as endogenous, so they are not seeking to identify a causal effect of unemployment.

A related literature examines the relationship between unemployment and participation in environmental organizations. Torgler et al. (2010) identify employment status as one variable that could conceptually associate either positively or negatively with environmental volunteerism. Indeed, the empirical evidence appears mixed. Using data from the World Values Survey, Torgler et al. (2011) find little evidence that employment status is associated with participation in environmental organizations. Fidrmuc and Gërxhani (2005)find unemployed individuals in Europe are less likely to actively participate in voluntary organizations; the magnitude of the effect is larger for Olsonian groups 
(which includes environmental organizations) than for Putnam groups (which includes religious organizations, sports clubs, and hobby clubs). Martinez and McMullin (2004) survey members of the Appalachian Trail Conference and find that active environmental volunteers who donate time to the organization are slightly less likely to be employed relative to members of the organization that only pay fees, although the difference is not statistically significant.

Several other papers have documented a relationship between individual level income and environmental protection and/or preferences. For example, Kahn (1998) finds the typical Kuznets U curve when analyzing the relationship between household income and vehicle emissions. And, many papers within the stated-preference contingent valuation literature have investigated the role of income in explaining environmental preferences (For example, Bulte et al., 2005; Whitehead, 1991; Popp, 2001). Here, many studies have found a positive association between income and willingness to pay for environmental amenities, but sometimes there is an insignificant relationship. Two other recent papers examine the relationship between income and environmental preferences but do not find a significant relationship (De Silva and Pownall, 2014; Ferreira and Moro, 2013). Thus, previous findings are mixed as to how income is associated with environmental preferences

\section{Data}

The data for this analysis come from two sources, Eurobarometer public opinion surveys (European Commission, 2012, 2014b) and the Eurostat database (2014). Eurobarometer surveys are conducted by the European Commission with the intent of monitoring public opinion in the Member States. There are Standard Eurobarometer surveys, conducted twice annually, and periodic Special Eurobarometer surveys on thematic issues. For this analysis, we utilize data from two Special Eurobarometer surveys concerning the environment.

Eurobarometer 68.2 was conducted from November 2007-January 2008 and interviewed 26,730 citizens from 25 EU countries. Eurobarometer 75.2 was conducted from April-May 2011 and interviewed 26,825 citizens from 27 EU countries. Both surveys utilized a multi-stage, random sampling design to attain samples that are representative of the EU population. The sample size in most countries is 1000 respondents for both surveys. All surveys were conducted in face-to-face interviews using detailed and uniform instructions and only one individual of a selected household was interviewed (Papacostas, 2012; European Commission, 2014a). Eurobarometer data files provide population size weighting variables so that one can conduct analysis representative of the EU population. The Eurobarometer primary data files are publicly available from GESIS. $\underline{3}$ 
Crucially, the Eurobarometer data files identify the geographic region of each individual using the EU NUTS (Nomenclature of territorial units for statistics) classifications. NUTS codes have various levels; NUTS-0 corresponds to the country level, NUTS-1 corresponds to major socio-economic regions within a country, NUTS-2 corresponds to basic regions within a NUTS-1 region, and NUTS-3 corresponds to small regions within a NUTS-2 region. For some smaller countries, such as Estonia, the EU has established only NUTS-0 level codes (Nomenclature of Territorial Units for Statistics, 2014). The Eurobarometer surveys provide NUTS-2 codes for each surveyed individual for all countries except Germany and UK, for which Eurobarometer provides NUTS-1 codes. Thus, we have NUTS-2 codes for Austria, Belgium, Bulgaria, Czech Republic, Denmark, Finland, France, Greece, Hungary, Italy, Netherlands, Poland, Portugal, Romania, Slovakia, Slovenia, Spain, and Sweden. We have NUTS-1 codes for Germany and UK. And we have NUTS-0 codes for Luxembourg, Cyprus, Ireland, Malta, Estonia, Latvia, and Lithuania. These are the geographic levels that we utilize for regional fixed effects in all regressions. $\underline{4}$

While Eurobarometer 68.2 and 75.2 are not identical in all ways, they do contain significant overlap. Specifically, they both ask a group of questions about environmental issues and recent PEB's and collect the same demographic information. Therefore, we pool both surveys together into one sample containing 53,555 individual level observations. Again, we emphasize that this sample is representative of the entire EU-27 population, given that we apply population weights when analyzing the data. As in any population representative sample, there are significant numbers of students, retirees, and individuals who are not part of the labor force. We are most interested in the question of how unemployment affects PEB so we limit our sample to individuals who are part of the labor force. After $^{-}$ limiting to members of the labor force, we have a sample of 29,539 individuals from the EU-27 countries.

Our key explanatory variable is unemployment status. The surveys actually report occupation status, and we infer unemployment status from that question. Possible employment categories on the surveys include employed, self-employed, and non-active. Within the non-active category, possible statuses include (1) responsible for ordinary shopping and looking after the home, or without any current occupation, not working, (2) student, (3) unemployed or temporarily not working, or (4) retired or unable to work through illness. Of these four possible non-active statuses, we only consider "unemployed or temporarily not working" to be unemployed. We consider individuals with one of the other three non-active statuses to be not part of the labor force, and hence excluded from our analysis. We treat employed and self-employed the same in that we code both as simply "employed." Aside from unemployment status, the surveys also provide information on gender, age, household size, 
and whether the individual lives in a rural area, a medium-sized town, or a large town/city. We include these in the analysis as controls.

Eurobarometer 68.2 and 75.2 ask a question about various pro-environmental behaviors. The question is phrased as, "Have you done any of the following during the past month for environmental reasons?" The exact wording of the 8 possible PEB's is as follows:

- Chosen an environmentally friendly way of traveling (by foot, bicycle, public transport)

- Reduced the consumption of disposable items (for example plastic bags, certain kind of packaging, etc.) - Separated most of your waste for recycling

- Cut down your water consumption (for example not leaving water running when washing the dishes or taking a shower, etc.)

- Cut down your energy consumption (for example turning down air conditioning or heating, not leaving appliances on stand-by, buying energy saving light bulbs, buying energy efficient appliances, etc.)

-Bought environmentally friendly products marked with an environmental label

- Chosen locally produced products or groceries

- Used my car less

We examine each of the eight PEB's separately as the dependent variable. We develop our predictions for how unemployment will affect each of these behaviors in the conceptual framework.

Finally, for our instrument, we merge in regional unemployment rates at the corresponding NUTS level. We obtain this variable from the Eurostat database for the years 2007 and 2011. Summary statistics for all variables are shown in Table 1.

Table 1. Descriptive statistics.

Variable

Personal characteristics

Unemployed

Male

Age

Household size

Medium town

Large town/city

Environmental behaviors

Environmentally friendly transportation
Obs Mean Std. dev. Min Max

$\begin{array}{lllll}29539 & 0.112 & 0.316 & 0 & 1 \\ 29539 & 0.498 & 0.500 & 0 & 1 \\ 29539 & 41.934 & 12.047 & 15 & 91 \\ 29539 & 2.896 & 1.422 & 1 & 20 \\ 29490 & 0.364 & 0.481 & 0 & 1 \\ 29490 & 0.289 & 0.453 & 0 & 1\end{array}$

295390.306

0.461 


\begin{tabular}{llllll} 
Variable & Obs & Mean & Std. dev. & Min & Max \\
\hline Reduce disposables & 29539 & 0.321 & 0.467 & 0 & 1 \\
Separate waste & 29539 & 0.600 & 0.490 & 0 & 1 \\
Reduce water usage & 29539 & 0.399 & 0.490 & 0 & 1 \\
Reduce energy usage & 29539 & 0.517 & 0.500 & 0 & 1 \\
Purchase environmentally labeled products & 29539 & 0.209 & 0.407 & 0 & 1 \\
Purchase local products & 29539 & 0.287 & 0.452 & 0 & 1 \\
Reduce car usage & 29539 & 0.180 & 0.384 & 0 & 1 \\
NUTS regional variable (instrument) & & & & & \\
Unemployment rate & 29035 & 8.434 & 4.484 & 2.1 & 30.1
\end{tabular}

\section{Conceptual framework}

The traditional economic perspective on PEB is to view it as a voluntary contribution to a public good (Clark et al., 2003; Turaga et al., 2010). Traditional economic models predict low levels of PEB because individuals have an incentive to free-ride on the contributions of others to the public good (Olson, 1965; Bergstrom et al., 1986). However, empirical studies find much higher levels of private contributions to public goods than these theories predict (Andreoni, 1988). In response, economists have built models where an individual receives a private benefit from contributing to a public good. Examples of the private benefit of giving include warm glow (Andreoni, 1990), self-image (Brekke et al.,

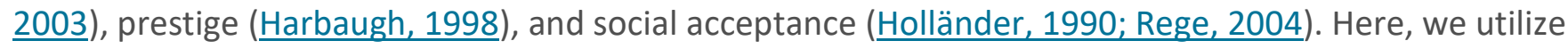
the framework of Brekke et al. (2003) to develop some testable implications.

Brekke et al. (2003) theorize that utility is increasing in leisure and in an individual's self-image as a socially responsible person, where self-image is a function of the deviation of one's public good effort from the morally ideal public good effort. The authors note that effort spent on the public good takes time away from leisure, so an individual will be making decisions comparing marginal utilities from leisure and public good effort. An individual then produces private contributions to the public good (PEB) using only effort $\underline{6}$ as an input. Here, it is important to recognize that the 8 different PEB's in our Eurobarometer application are not uniform in their production functions. Some behaviors require mainly time/effort while others require mainly monetary contributions.

Unemployment increases the amount of non-labor related time available (relaxes the time constraint) and also decreases the budget constraint. Since an individual receives utility from increases to self- 
image, we would expect a relaxed time constraint to result in more time devoted to the public good effort. Therefore, PEB's that require mainly time and/or effort would be expected to increase with unemployment. The behaviors that most clearly require time and/or effort are environmentally friendly transportation, reducing water usage, reducing energy usage, reducing car usage, and separating waste for recycling. Next, a decrease in the budget constraint leaves the individual with less money to purchase private consumption goods and to make financial contributions to the public good. Assuming that public environmental quality and self-image are normal goods, this would lead to a decrease in the level of monetary contributions to producing PEB's. Hence, behaviors require mainly financial inputs would be expected to decrease with unemployment. The two behaviors from the survey that most clearly require financial inputs are purchasing environmentally labeled products and purchasing local products. Both of these products tend to command premiums relative to their substitutes.

Although the survey phrases the question to gather information on behaviors performed only for environmental reasons, it is worth noting that some of the behaviors potentially produce cost savings in addition to the environmental benefits; this includes environmentally friendly transportation, reducing water usage, reducing energy usage, and reducing car usage. With a decrease in the opportunity cost of time, we would expect unemployed individuals to devote more time/effort to identifying potential cost-savings. An analogy can be drawn to other cost-saving behaviors such as coupon clipping. We would expect individuals with lower incomes to devote more time/effort to finding coupons because their opportunity cost of time is lower. Regardless of the motivation, both underlying motivators would cause PEB's in this category to increase when an individual becomes unemployed.

We summarize the classification of the PEB's in Table 2. The one behavior missing from this table is reducing the consumption of disposable items. The reason for its absence is that there are arguments that this is cost-saving and arguments that this requires a cost premium. Similarly, there are arguments that this behavior is time/effort consuming and arguments that it does not require much attention. Thus, our testable predictions for the other 7 behaviors are that (1) unemployment should have a positive impact on environmentally friendly transport, reducing water usage, reducing energy usage, reducing car usage, and separating waste, and (2) unemployment should have a negative impact on the purchasing of labelled products and the purchasing of local products. 
Table 2. PEB categorization.

\section{Cost dimension}

\section{Cost saving}

Environmentally friendly

transport

Time/effort consuming

Time

dimension

Reduce energy usage

Reduce car usage

\section{Cost neutral Cost premium}

Separate

waste

Purchase labeled

Not time/effort

products

consuming

Purchase local

products

\section{Estimation strategy and results}

We are interested in the effect of individual unemployment status on PEB. It is quite possible that there are unobservable characteristics of individuals that are correlated with both the probability of being unemployed and the extent of PEB. For example, innate motivation or general conscientiousness could affect how likely it is for an individual to be employed and also could influence the extent of behaviors in many areas of life, including PEB. Thus, we adopt an instrumental variables approach to deal with the potential endogeneity of individual unemployment status.

As mentioned in the data description, we analyze each PEB individually; thus, we have 8 dichotomous dependent variables. Because of the dichotomous nature of the dependent variables, one could utilize a probit model. However, our key explanatory variable, unemployment status, is dichotomous. It is well know that the probit model does not produce consistent estimates with a discrete endogenous regressor. Therefore, all IV estimates come from linear probability models. The main downside of the linear probability model is that it can predict values of the dependent variable that fall outside of the range of $0-1$. However, the benefit of the linear probability model is that it can handle a discrete endogenous regressor. Moreover, as discussed by Angrist and Pischke (2009), the linear probability model generally produces marginal effects that are quite similar to the probit model.

Thus, we specify our regression model for each of the 8 individual PEB's, EBi, as

(1)

$$
\mathrm{EB}_{i}=\alpha+\text { Bunemployed }_{i}+\gamma^{\prime} X_{i}+\delta \text { NUTS }_{j}+\theta \text { Year }_{2011}+\varepsilon_{i}
$$


where unemployed is the endogenous unemployment status of individual $i$, Xiis a vector of exogenous explanatory variables including gender, age, household size, and whether the individual lives in a rural area, a medium-sized town, or a large town/city, NUTSj are NUTS level fixed effects, Year2011 is a survey fixed effect for the 2011 survey, and $\varepsilon i$ is the error term. Any time invariant factors at the NUTS level that are associated with pro-environmental behavior will be captured by the NUTS level fixed effects. Similarly, any factors that are common across NUTS regions and lead to changes in pro-environmental behavior between 2007 and 2011 will be controlled by the survey fixed effect.

We instrument for individual unemployment status with NUTS level unemployment rate. Hence, our first stage equation is

$$
\text { unemployed }_{i}=\varphi_{0}+\varphi_{1} \mathrm{UR}_{j}+\varphi_{2}^{\prime} X_{i}+\varphi_{3} \mathrm{NUTS}_{j}+\varphi_{4} \mathrm{Year}_{2011}+\omega_{i},
$$

where $\mathrm{UR}_{j}$ is the unemployment rate in NUTS region $j$, and $\omega_{i}$ is an error term.

Since individual unemployment status is dichotomous, this first stage conditional expectation function (CEF) is probably nonlinear. However, only OLS estimation of this first stage is guaranteed to produce first-stage residuals that are uncorrelated with fitted values and covariates. Assuming that the first stage CEF is probit and plugging in fitted values could lead to first-stage residuals that are correlated with fitted values and covariates. This is the commonly termed "forbidden regression." Thus, it is common to use 2SLS to estimate this model, recognizing that we do not need to be concerned with whether the first-stage CEF really is linear (Angrist and Pischke, 2009).

Notice that, if we only had data from one year (2007, for example), we could not identify this equation when including NUTS region fixed effects. The NUTS region fixed effects would be perfectly collinear with the NUTS level unemployment rate. Thus, it is crucial for our identification that we have observations from individuals from within the same NUTS regions from two separate survey years. In essence, the identification in the first stage regression is coming from variation in the unemployment rate within a region over time. In normal circumstances, one may expect there to be little variation within a NUTS region over a relatively short amount of time. However, the global macroeconomic shocks that took place beginning in 2008 provide an exogenous source of variation to the first stage equation.

Our instrument is valid if it is correlated with individual unemployment status but has no direct effect on PEB. The effect of the instrument on PEB must work through the channel of individual 
unemployment. The correlation of the instrument with individual unemployment status is straightforward. A higher regional unemployment rate means that it will be more difficult to find a job, and hence the probability of individual unemployment will increase. There is strong evidence of this association, as we subsequently discuss in the context of the first stage results.

It is not possible to statistically demonstrate that the effect of the instrument on PEB works through the channel of individual unemployment. - We maintain, however, that one's environmental attitudes and behaviors are mainly influenced by one's own financial (and unemployment) situation. As explained previously, theory predicts that PEB will change when one's income changes due to a shifting budget constraint and changing opportunity cost of time. On the other hand, it is unclear how a similar mechanism would operate in the case of a deteriorating regional macroeconomic employment situation. Consider the following hypothetical example. Daniel and John are two European individuals. Daniel lives in a region that happens to be doing comparatively well economically where the unemployment rate has been falling relative to the EU average. However, Daniel is unlucky and loses his job. John is in a region that happens to be doing comparatively poorly economically where the unemployment rate has been rising relative to the EU average. However, John is a lucky individual with a steady job. We ask, which of these individuals is more likely to change their PEB due to changing economic circumstances, Daniel or John? We think the answer is Daniel because his individual unemployment status has directly and substantially affected his budget constraint while any macroeconomic benefits are diffuse. John, on the other hand, has an unaffected budget constraint and any macroeconomic difficulties would be diffuse. Furthermore, is the rising unemployment rate in John's region likely to affect his PEB at all as long as he retains his job? We cannot say with absolute certainty that there will be no effect here, but we propose that any effects would be quite indirect and small in magnitude. Therefore, we believe that we are justified in the choice of regional unemployment as an instrument. $\underline{9}$

In Tables 3-6, we report regression results for Eq. (1) for each PEB. We do this for three different specifications for each group. 10 As a baseline (column 1), we ignore the endogeneity of unemployment status and estimate a linear probability model.11 2SLS is known to be a consistent, but biased estimator of the causal effect of interest.12 Also, the bias of 2SLS increases as the number of instruments increases. Thus, we present results for the just-identified case of one instrument, NUTS level unemployment rate, in Column 2.13 We choose to cluster standard errors at the country level in all regressions because there could be correlation in the error terms between NUTS regions within a country.

Table 3. Regression results: purchase environmentally labeled products and purchase local products. 


\begin{tabular}{|c|c|c|c|c|c|c|}
\hline \multirow[t]{3}{*}{ Variables } & \multicolumn{3}{|c|}{$\begin{array}{l}\text { Purchase environmentally labeled } \\
\text { products }\end{array}$} & \multicolumn{3}{|c|}{ Purchase local products } \\
\hline & (1) & (2) & (3) & (4) & (5) & (6) \\
\hline & OLS & 2SLS & 2SLS & OLS & 2SLS & 2SLS \\
\hline \multirow[t]{2}{*}{ Unemployed } & $-0.0512^{* * *}$ & $-0.210^{* *}$ & $-0.311^{* * *}$ & $-0.0583^{* *}$ & -0.347 & -0.302 \\
\hline & $(0.00756)$ & $(0.0953)$ & $(0.0890)$ & $(0.0226)$ & $(0.323)$ & $(0.289)$ \\
\hline \multirow[t]{2}{*}{ Male } & $-0.0557^{* * *}$ & $-0.0598^{* * *}$ & $-0.0615^{* * *}$ & $-0.0465^{* * *}$ & $-0.0540^{* * *}$ & $-0.0524^{* * *}$ \\
\hline & $(0.00953)$ & $(0.0103)$ & $(0.0115)$ & $(0.00736)$ & $(0.0122)$ & $(0.0121)$ \\
\hline \multirow[t]{2}{*}{ Age } & $0.000740^{* *}$ & 0.000391 & 0.000228 & $0.00239^{* * *}$ & $0.00176^{* * *}$ & $0.00188^{* * *}$ \\
\hline & $(0.000298)$ & $(0.000328)$ & $(0.000309)$ & $(0.000393)$ & $(0.000626)$ & $(0.000601)$ \\
\hline \multirow[t]{2}{*}{$\begin{array}{l}\text { Household } \\
\text { size }\end{array}$} & 0.00113 & 0.000207 & -0.00112 & 0.00298 & 0.00129 & 0.00164 \\
\hline & $(0.00267)$ & $(0.00306)$ & $(0.00305)$ & $(0.00219)$ & $(0.00295)$ & $(0.00286)$ \\
\hline \multirow[t]{2}{*}{ Medium town } & 0.00467 & 0.00309 & 0.000350 & $-0.0366^{* *}$ & $-0.0395^{* *}$ & $-0.0385^{* *}$ \\
\hline & $(0.0137)$ & $(0.0133)$ & $(0.0126)$ & $(0.0171)$ & $(0.0162)$ & $(0.0166)$ \\
\hline \multirow[t]{2}{*}{$\begin{array}{l}\text { Large } \\
\text { town/city }\end{array}$} & 0.0215 & 0.0166 & 0.00935 & $-0.0651^{* * *}$ & $-0.0740^{* * *}$ & $-0.0724^{* * *}$ \\
\hline & $(0.0176)$ & $(0.0184)$ & $(0.0171)$ & $(0.0207)$ & $(0.0157)$ & $(0.0153)$ \\
\hline \multirow[t]{2}{*}{ Constant } & $0.284^{* * *}$ & $0.315^{* * *}$ & $0.334^{* * *}$ & $0.306^{* * *}$ & $0.361^{* * *}$ & $0.351^{* * *}$ \\
\hline & $(0.0173)$ & $(0.0278)$ & $(0.0276)$ & $(0.0269)$ & $(0.0505)$ & $(0.0451)$ \\
\hline Observations & 28,987 & 28,987 & 28,583 & 28,987 & 28,987 & 28,583 \\
\hline SE clustered & Country & Country & Country & Country & Country & Country \\
\hline IV & - & UR & unemployed" & - & UR & unemployed" \\
\hline \multicolumn{7}{|l|}{$\begin{array}{l}\text { IV exogeneity } \\
\text { tests }\end{array}$} \\
\hline $\begin{array}{l}\text { Robust } \\
\text { regression F }\end{array}$ & - & 2.48 & 12.02 & - & 1.15 & 0.836 \\
\hline (p-value) & - & $(0.13)$ & $(0.0019)$ & - & $(0.29)$ & $(0.369)$ \\
\hline $\begin{array}{l}\text { Robust standard } \\
\text { Probability weigh } \\
\text { All regressions in } \\
\text { UR = NUTS unem } \\
{ }^{*} p<0.1 . \\
{ }^{*} p<0.05 .\end{array}$ & $\begin{array}{l}\text { errors in par } \\
\text { hts supplied } \\
\text { clude NUTS } \\
\text { aployment ra }\end{array}$ & $\begin{array}{l}\text { rentheses are } \\
\text { by Eurobaror } \\
\text { Region FE an } \\
\text { te. }\end{array}$ & $\begin{array}{l}\text { clustered at } \\
\text { neter used in } \\
\text { d Survey Year }\end{array}$ & $\begin{array}{l}\text { the country le } \\
\text { all regression } \\
\text { FE. }\end{array}$ & $\begin{array}{l}\text { evel. } \\
\text { ns. }\end{array}$ & \\
\hline
\end{tabular}


$* * p<0.01$.

Table 4. Regression results: reduce energy usage and reduce car usage.

Variables

Reduce energy usage

(1)

(2)

2SLS

$-0.0783^{* * *} \quad 0.771^{* * *}$

Unemployed

Male

Age

$(0.0275)$

(0.292)

(0.194)

(0.0114)

(0.104)

$(0.0914)$

$$
-0.0378^{* * *}
$$

$(0.00703) \quad(0.0106)$

$-0.0247^{* * *}$

$0.0230^{*}$

$0.0355^{* *}$

$0.0349^{* * *}$

$0.00454^{* * *}$

(0.00677)

$(0.00631)$

(0.00847) (0.00687)

Household size

$$
\begin{array}{llllll}
0.00226 & 0.00720 & 0.00398 & 0.00388 & 0.00666 & 0.00618 \\
(0.00215) & (0.00522) & (0.00438) & (0.00368) & (0.00482) & (0.00452)
\end{array}
$$

$\begin{array}{lllllll}\text { Medium town } & -0.00770 & 0.000748 & -0.000852 & 0.0108 & 0.0155 & 0.0111\end{array}$

$$
\begin{array}{llllll}
(0.00995) & (0.0152) & (0.0134) & (0.0108) & (0.0136)
\end{array}
$$

$\begin{array}{lllllll}\text { Large town/city } & -0.0180 & 0.00832 & -0.00490 & 0.00690 & 0.0217 & 0.0142\end{array}$

$$
\begin{array}{llllll}
(0.0134) & (0.0196) & (0.0162) & (0.0148) & (0.0162) & (0.0144)
\end{array}
$$

Constant

$$
\begin{array}{llllll}
0.334^{* * *} & 0.171^{* * *} & 0.230^{* * *} & 0.211^{* * *} & 0.119^{* * *} & 0.137^{* * *} \\
(0.0184) & (0.0624) & (0.0332) & (0.0209) & (0.0329) & (0.0249)
\end{array}
$$

$\begin{array}{lllllll}\text { Observations } & 28,987 & 28,987 & 28,583 & 28,987 & 28,987 & 28,583 \\ \text { SE clustered } & \text { Country } & \text { Country } & \text { Country } & \text { Country } & \text { Country } & \text { Country } \\ \text { IV } & - & \text { UR } & \text { unemployed“ } & - & \text { UR } & \text { unemployed" }\end{array}$




$\begin{array}{llllll}(1) & (2) & (3) & (4) & (5) & (6) \\ \text { OLS } & 2 S L S & 2 S L S & \text { OLS } & 2 S L S & 2 S L S\end{array}$

\section{IV exogeneity tests}

$\begin{array}{lllllll}\text { Robust regression F } & - & 19.61 & 12.56 & - & 48.49 & 19.79 \\ (p \text {-value } & - & (0.0002) & (0.0016) & - & (0.0000) & (0.0002)\end{array}$

Robust standard errors in parentheses are clustered at the country level. Probability weights supplied by Eurobarometer used in all regressions. All regressions include NUTS Region FE and Survey Year FE.

UR = NUTS unemployment rate.

${ }^{*} p<0.1$.

$* p<0.05$.

$* * p<0.01$.

Table 5. Regression results: reduce disposables and separate waste.

\begin{tabular}{|c|c|c|c|c|c|c|}
\hline \multirow[t]{3}{*}{ Variables } & \multicolumn{3}{|c|}{ Reduce disposables } & \multicolumn{3}{|c|}{ Separate waste } \\
\hline & (1) & (2) & (3) & (4) & (5) & (6) \\
\hline & OLS & 2SLS & 2SLS & OLS & 2SLS & $2 S L S$ \\
\hline \multirow[t]{2}{*}{ Unemployed } & -0.0430 & -0.324 & -0.276 & $-0.100^{* * *}$ & 0.226 & 0.0839 \\
\hline & $(0.0289)$ & $(0.237)$ & $(0.204)$ & $(0.0234)$ & $(0.198)$ & $(0.116)$ \\
\hline \multirow[t]{2}{*}{ Male } & $-0.0673^{* * *}$ & $-0.0747^{* * *}$ & $-0.0757^{* * *}$ & $-0.0497^{* * *}$ & $-0.0412^{* * *}$ & $-0.0461^{* * *}$ \\
\hline & $(0.0119)$ & $(0.0132)$ & $(0.0128)$ & (0.00938) & $(0.0117)$ & $(0.00941)$ \\
\hline \multirow[t]{2}{*}{ Age } & $0.00149^{* * *}$ & 0.000871 & 0.000816 & $0.00278^{* * *}$ & $0.00350^{* * *}$ & $0.00326^{* * *}$ \\
\hline & $(0.000526)$ & $(0.000671)$ & $(0.000808)$ & $(0.000649)$ & $(0.000737)$ & $(0.000652)$ \\
\hline \multirow[t]{2}{*}{ Household size } & 0.00293 & 0.00129 & 0.000737 & $0.00619^{*}$ & $0.00809^{*}$ & 0.00639 \\
\hline & $(0.00332)$ & $(0.00278)$ & $(0.00314)$ & $(0.00319)$ & $(0.00479)$ & $(0.00444)$ \\
\hline \multirow[t]{2}{*}{ Medium town } & -0.00847 & -0.0113 & -0.00996 & $-5.35 e-06$ & 0.00324 & -0.00132 \\
\hline & $(0.0152)$ & $(0.0149)$ & $(0.0158)$ & $(0.0166)$ & $(0.0162)$ & $(0.0164)$ \\
\hline \multirow[t]{2}{*}{$\begin{array}{l}\text { Large } \\
\text { town/city }\end{array}$} & 0.00428 & -0.00444 & -0.00545 & -0.0182 & -0.00806 & -0.0131 \\
\hline & $(0.0233)$ & $(0.0218)$ & (0.0195) & (0.0199) & $(0.0223)$ & $(0.0206)$ \\
\hline
\end{tabular}




\begin{tabular}{|c|c|c|c|c|c|c|}
\hline \multirow[t]{3}{*}{ Variables } & \multicolumn{2}{|c|}{ Reduce disposables } & \multicolumn{4}{|c|}{ Separate waste } \\
\hline & (1) & (2) & (3) & (4) & (5) & (6) \\
\hline & OLS & 2SLS & 2SLS & OLS & 2SLS & 2SLS \\
\hline \multirow[t]{2}{*}{ Constant } & $0.266^{* * *}$ & $0.320^{* * *}$ & $0.322^{* * *}$ & $0.702^{* * *}$ & $0.640^{* * *}$ & $0.670^{* * *}$ \\
\hline & $(0.0303)$ & $(0.0340)$ & $(0.0471)$ & $(0.0251)$ & $(0.0528)$ & $(0.0410)$ \\
\hline Observations & 28,987 & 28,987 & 28,583 & 28,987 & 28,987 & 28,583 \\
\hline IV & - & UR & unemployed" & - & UR & unemployed" \\
\hline \multicolumn{7}{|l|}{$\begin{array}{l}\text { IV exogeneity } \\
\text { tests }\end{array}$} \\
\hline $\begin{array}{l}\text { Robust } \\
\text { regression F }\end{array}$ & - & 1.93 & 1.46 & - & 4.58 & 2.30 \\
\hline (p-value) & - & $(0.18)$ & $(0.238)$ & - & $(0.042)$ & $(0.142)$ \\
\hline
\end{tabular}

Robust standard errors in parentheses are clustered at the country level.

Probability weights supplied by Eurobarometer used in all regressions.

All regressions include NUTS Region FE and Survey Year FE.

UR = NUTS unemployment rate.

$p<0.1$.

${ }^{* *} p<0.05$.

$* * p<0.01$.

Table 6. Regression results: environmentally friendly transportation and reduce water usage.

Variables Environmentally friendly transportation Reduce water usage

\begin{tabular}{|c|c|c|c|c|c|c|}
\hline & (1) & (2) & (3) & (4) & (5) & (6) \\
\hline & OLS & 2SLS & $2 S L S$ & OLS & 2SLS & 2SLS \\
\hline Unemployed & $0.0297=$ & -0.0942 & -0.0740 & -0.0346 & 0.00634 & 0.0155 \\
\hline & $(0.0165)$ & $(0.125)$ & $(0.124)$ & (0.0220) & $(0.175)$ & $(0.140)$ \\
\hline Male & $-0.0186^{* * * *}$ & $-0.0219^{* * *}$ & $-0.0240^{* * *}$ & $-0.0767^{* * *}$ & $-0.0756 * *$ & $-0.0770^{* * * *}$ \\
\hline & $(0.00637)$ & $(0.00582)$ & $(0.00552)$ & $(0.0133)$ & $(0.0155)$ & $(0.0140)$ \\
\hline Age & -0.000414 & -0.000686 & -0.000686 & $0.00285^{* * *}$ & $0.00294^{* * *}$ & $0.00311^{* * *}$ \\
\hline & $(0.000442)$ & $(0.000422)$ & $(0.000458)$ & $(0.000528)$ & $(0.000528)$ & $(0.000535)$ \\
\hline Household size & $-0.00670^{* *}$ & $-0.00742^{* * *}$ & $-0.00840^{* * *}$ & 0.00445 & 0.00469 & 0.00410 \\
\hline & $(0.00254)$ & $(0.00244)$ & $(0.00275)$ & $(0.00345)$ & $(0.00301)$ & $(0.00292)$ \\
\hline Medium town & $0.0510^{* * *}$ & $0.0498^{* * *}$ & $0.0473^{* * *}$ & -0.0144 & -0.0139 & -0.0133 \\
\hline & $(0.0152)$ & $(0.0156)$ & $(0.0153)$ & (0.0151) & $(0.0162)$ & (0.0169) \\
\hline
\end{tabular}




\begin{tabular}{|c|c|c|c|c|c|c|}
\hline \multirow[t]{3}{*}{ Variables } & \multicolumn{3}{|c|}{ Environmentally friendly transportation } & \multicolumn{3}{|c|}{ Reduce water usage } \\
\hline & (1) & (2) & (3) & (4) & (5) & (6) \\
\hline & OLS & 2SLS & 2SLS & OLS & 2SLS & 2SLS \\
\hline \multirow[t]{2}{*}{ Large town/city } & $0.0966^{* * *}$ & $0.0927^{* * *}$ & $0.0898^{* * *}$ & -0.0197 & -0.0185 & -0.0230 \\
\hline & $(0.0215)$ & $(0.0232)$ & $(0.0241)$ & $(0.0201)$ & $(0.0227)$ & $(0.0218)$ \\
\hline \multirow[t]{2}{*}{ Constant } & $0.426^{* * *}$ & $0.450^{* * *}$ & $0.454^{* * *}$ & $0.296^{* * *}$ & $0.288^{* * *}$ & $0.281^{* * *}$ \\
\hline & $(0.0236)$ & $(0.0293)$ & $(0.0317)$ & $(0.0137)$ & $(0.0352)$ & $(0.0312)$ \\
\hline Observations & 28,987 & 28,987 & 28,583 & 28,987 & 28,987 & 28,583 \\
\hline SE clustered & Country & Country & Country & Country & Country & Country \\
\hline IV & - & UR & unemployed" & - & UR & unemployed \\
\hline \multicolumn{7}{|l|}{ IV exogeneity tests } \\
\hline Robust regression F & - & 0.814 & 0.689 & - & 0.0517 & 0.132 \\
\hline (p-value) & - & $(0.376)$ & $(0.415)$ & - & $(0.822)$ & $(0.719)$ \\
\hline $\begin{array}{l}\text { Robust standard error } \\
\text { Probability weights su } \\
\text { All regressions include } \\
\text { UR }=\text { NUTS unemployr } \\
*_{p}<0.1 . \\
* * p<0.05 . \\
* * * p<0.01 .\end{array}$ & $\begin{array}{l}\text { rs in parent } \\
\text { pplied by } \\
\text { NUTS Reg } \\
\text { ment rate. }\end{array}$ & $\begin{array}{l}\text { ses are clus } \\
\text { obaromete } \\
\text { FE and Sur }\end{array}$ & $\begin{array}{l}\text { ed at the coun } \\
\text { ed in all regres } \\
\text { Year FE. }\end{array}$ & $\begin{array}{l}\text { try level. } \\
\text { ssions. }\end{array}$ & & \\
\hline
\end{tabular}

Although 2SLS estimates are consistent when running a first stage OLS regression of Eq. (2), there is a more efficient alternative. In the alternative, we run a preliminary probit regression of Eq. (2). Following Chi and Drewianka (2014), call this the "Oth stage" regression so as to avoid confusion with the normal first stage of 2SLS. Then, we predict the fitted values of unemployedifrom this probit regression, calling them unemployedi“. Next, we run the OLS first-stage regression of

(3)

$$
\text { unemployed }_{i}=\pi_{0}+\pi_{1} \text { unemployed }_{i}+\pi_{2}^{\prime} X_{i}+\pi_{3} \text { NUTS }_{j}+\pi_{4} \text { Year }_{2011}+\omega_{i} \text {. }
$$

Note that this approach is different from the aforementioned "forbidden regression." Here, the approach is to use UR not as an instrument, but as an excluded variable in the non-linear probit model of the endogenous individual level employment outcome. The resulting predicted values from the nonlinear regression are used as instruments in standard 2SLS. Finally, we run the usual second stage 
regression of Eq. (1) using the fitted values from Eq. (3). As discussed in Angrist and Pischke (2009), this estimator is consistent. 14 However, since it capitalizes on the non-linearity of Eq. (2), this estimator can provide better precision in the resulting estimates than the standard 2SLS with a discrete endogenous regressor. We present these results in column 3 of Tables 3-6.

The bias of 2SLS is larger when the first stage is weak, so it is important to closely examine the first stage. We provide evidence of a strong first stage in Table 7. The first stage regression is the same for all of our PEB dependent variables; the two columns correspond to the first stages of columns 2 and 3 of Tables 3-6. In both cases, the first stage F-statistic is well above the Stock et al. (2002) rule of thumb F-statistic of 10. Furthermore, the coefficients on NUTS unemployment rate and NUTS early school leavers are statistically significant and of the conceptually correct sign. 15

Table 7. First stage regression results.

\begin{tabular}{|c|c|c|}
\hline \multirow[t]{3}{*}{ Variables } & (1) & (2) \\
\hline & First stage & First stage \\
\hline & Unemployed & Unemployed \\
\hline \multirow[t]{2}{*}{ Male } & $-0.0260^{* * *}$ & 0.0011 \\
\hline & $(0.00808)$ & $(0.0086)$ \\
\hline \multirow[t]{2}{*}{ Age } & $-0.00217^{* * *}$ & 0.0000758 \\
\hline & $(0.000552)$ & $(0.00065)$ \\
\hline \multirow[t]{2}{*}{ Household size } & -0.00589 & 0.00123 \\
\hline & $(0.00380)$ & $(0.0043)$ \\
\hline \multirow[t]{2}{*}{ Medium town } & -0.00931 & -0.0012 \\
\hline & $(0.00995)$ & $(0.00945)$ \\
\hline \multirow[t]{2}{*}{ Large town/city } & $-0.0299^{*}$ & -0.00069 \\
\hline & $(0.0167)$ & $(0.0159)$ \\
\hline \multirow[t]{2}{*}{ NUTS unemployment rate } & $0.0126^{* * *}$ & - \\
\hline & $(0.00210)$ & \\
\hline \multirow[t]{2}{*}{ unemployed" } & - & $1.048^{* * *}$ \\
\hline & & $(0.097)$ \\
\hline \multirow[t]{2}{*}{ Constant } & $0.154^{* * *}$ & -0.0069 \\
\hline & $(0.0278)$ & $(0.0304)$ \\
\hline
\end{tabular}


Variables

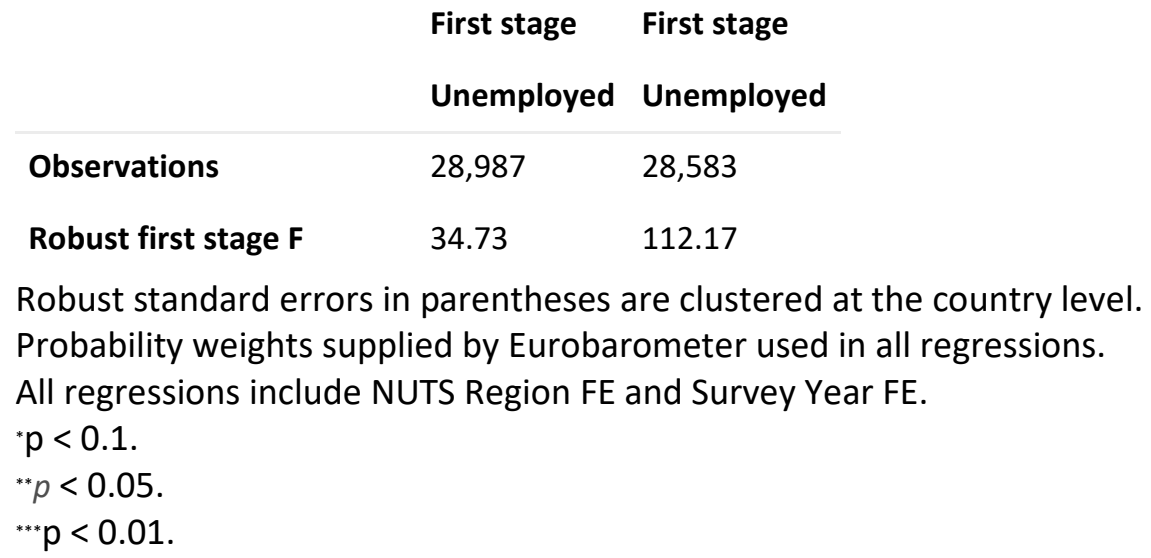

First stage First stage

Unemployed Unemployed

Observations

28,987

34.73

28,583

Robust first stage $F$

112.17

Robust standard errors in parentheses are clustered at the country level. Probability weights supplied by Eurobarometer used in all regressions. All regressions include NUTS Region FE and Survey Year FE.

${ }^{*} p<0.1$.

${ }^{* *} p<0.05$.

${ }^{* * *} p<0.01$.

(1) (2)

We first focus on column 1 where we treat unemployment as exogenous. Looking across Tables 3-6, we see negative and significant coefficients on unemployment for four of the behaviors, negative and insignificant coefficients for three of the behaviors, and a significant positive coefficient only for environmentally friendly transportation. The majority of negative coefficients here is perhaps not surprising. If people who are observed to be unemployed also tend to be less motivated or conscientious, we may expect them to be less likely to engage in many different types of behavior. Thus, the negative OLS coefficients could simply be measures of general apathy.

Next, we examine the LATE for the PEB's that are predicted to be negatively impacted by unemployment. These are the behaviors that demand a cost premium-purchase of environmentally labeled products and purchase of local products (Table 3 ). Here, the estimated average causal effect in the IV regressions is of the same sign as the OLS regressions. That the IV estimate is several times larger than the OLS estimate implies that unobservable characteristics actually play a role in attenuating the observed association between unemployment and these PEB's. In other words, the omitted variables make the OLS coefficient "too small" relative to the causal effect. In Table 3 , we see that unemployment decreases the probability of purchasing environmentally labeled products by about -0.21 to -0.31 , depending on the specification. The magnitude of the LATE is quite similar in Table 3 for the purchase of local products. However, the estimates are also noisier and not significant at conventional levels. These magnitudes are large; among employed individuals, the mean probability of purchasing labeled products is 0.218 and the mean probability of purchasing local products is 0.294 .

Now we turn to the LATE for the time/effort intensive PEB's that are predicted to be positively affected by unemployment: environmentally friendly transportation, reducing water usage, reducing energy 
usage, reducing car usage, and separating waste for recycling. The LATE is positive and statistically significant for reducing energy usage and reducing car usage (Table 4). Furthermore, the estimated LATE's are large in magnitude for these two PEB's. Table 4 shows that unemployment leads to a $0.48-$ 0.77 increase in the probability of reducing energy usage and a $0.35-0.47$ increase in the probability of reducing car usage. For comparison, the LATE is roughly the same size as the sample mean of reducing energy usage for employed individuals (0.524) and twice as large as the sample mean of reducing car usage for employed individuals (0.183). IV exogeneity tests provide strong evidence that individual unemployment status is endogenous for these two PEB's.

As seen in Table 5, the LATE is positive but statistically insignificant for the case of separating waste for recycling. One plausible explanation for this result is that recycling sometimes costs individuals money. That is, with some systems, individuals have to pay for recycling service. This would work against finding a statistically significant effect here. Table 6 shows that there is basically 0 effect of unemployment for reductions in water usage. Similarly, we see a comparatively small and statistically insignificant LATE in Table 6 for environmentally friendly transportation. It is not clear why these two behaviors are not affected by unemployment to the same extent as the others, but this would interesting to study further in future work.

We note that, with the exception of environmentally friendly transportation, we find negative coefficients in the OLS regressions for these time/effort intensive behaviors. This is important because it shows that we would come to the wrong conclusion about unemployment's effect on PEB if we failed to acknowledge the endogeneity of unemployment. Once accounting for this endogeneity through IV regression, we see that the causal effect of unemployment on these behaviors is either positive or zero. Thus, ignoring the endogeneity of unemployment would lead us to miss valuable insights into when we can expect PEB to increase.

As for demographics, we find robust results across almost all of the PEB's that males engage in less PEB and older individuals engage in more PEB. The gender result is consistent with previous findings (De Silva and Pownall, 2014; Brecard et al., 2009; Dietz et al., 2002; Eisler et al., 2003; Hunter et al., 2004; Johnson et al., 2004; Zelezny et al., 2000). The age result is less expected as we often think of younger individuals being more environmentally focused. However, the magnitude of the estimated age effect is small. Adding a decade to one's age leads to approximately a 0.01-0.03 increase in the probability of PEB, depending on the specific PEB. 


\section{Discussion}

To recap, we have found that unemployment leads to a decrease in some PEB's that require a cost premium and an increase in some PEB's that require more time/effort. As noted in the conceptual framework, most of the behaviors that require more time/effort also have the potential to deliver cost savings. Here, we attempt to discriminate between these two potential explanations for the behaviors that increase and reinforce the reason for the PEB's that decrease. In addition to the PEB questions on the Eurobarometer surveys, there are several questions about what role environmental issues play in individuals' lives. These questions can help us determine the underlying motivation for behavior of unemployed individuals.

We first examine the following two questions, "Please tell me whether you totally agree, tend to agree, tend to disagree, or totally disagree with the following statements." (1) "Environmental problems have a direct effect on your daily life," and (2) "You are ready to buy environmentally friendly products even if they cost a little bit more." In each case, we group "totally agree" and "tend to agree" together as "yes" and "tend to disagree" and "totally disagree" together as "no." Then, we estimate a linear probability model using 2SLS to see the causal effect of individual unemployment on the answer to the question. Here, we report results for the predicted probit IV regression approach (Table 8). $\underline{16}$ Columns 1 and 2 of Table 8 show results for these two questions; in each case, individual unemployment causes an approximate 30 percentage point decrease in the probability of answering yes to the question. The direct daily effect question provides evidence that environmental issues become less salient when an individual is unemployed. As would be expected, the buying environmentally friendly products question provides evidence that cost is important to unemployed individuals. This reinforces our earlier findings that unemployment tends to decrease PEB's that primarily require monetary contributions as inputs.

Table 8. Regression results: supplementary questions with predicted probit IV.

\begin{tabular}{llllll} 
Variables & $\mathbf{( 1 )}$ & $\mathbf{( 2 )}$ & $\mathbf{( 3 )}$ & $\mathbf{( 4 )}$ & $\mathbf{( 5 )}$ \\
& $\begin{array}{l}\text { Second stage } \\
\text { Direct daily } \\
\text { effect }\end{array}$ & $\begin{array}{l}\text { Second stage } \\
\text { Buy green with higher } \\
\text { cost }\end{array}$ & $\begin{array}{l}\text { Second stage } \\
\text { Life quality } \\
\text { environment }\end{array}$ & $\begin{array}{l}\text { Second stage } \\
\text { Life quality } \\
\text { economic }\end{array}$ & $\begin{array}{l}\text { Second stage } \\
\text { Life quality } \\
\text { social }\end{array}$ \\
\hline Unemployed & $-0.307^{* * *}$ & $-0.298^{* * *}$ & $-0.335^{* * *}$ & $0.130^{*}$ & 0.0197 \\
& $(0.105)$ & $(0.0992)$ & $(0.103)$ & $(0.0756)$ & $(0.0624)$ \\
Male & $-0.0175^{* * *}$ & $-0.0323^{* * *}$ & $-0.0261^{* * *}$ & 0.00152 & $-0.0157^{* *}$ \\
& $(0.00496)$ & $(0.0102)$ & $(0.00775)$ & $(0.00634)$ & $(0.00717)$
\end{tabular}




\begin{tabular}{|c|c|c|c|c|c|}
\hline \multirow[t]{3}{*}{ Variables } & (1) & (2) & (3) & (4) & (5) \\
\hline & Second stage & Second stage & Second stage & Second stage & Second stage \\
\hline & $\begin{array}{l}\text { Direct daily } \\
\text { effect }\end{array}$ & $\begin{array}{l}\text { Buy green with higher } \\
\text { cost }\end{array}$ & $\begin{array}{l}\text { Life quality } \\
\text { environment }\end{array}$ & $\begin{array}{l}\text { Life quality } \\
\text { economic }\end{array}$ & $\begin{array}{l}\text { Life quality } \\
\text { social }\end{array}$ \\
\hline \multirow[t]{2}{*}{ Age } & 0.000740 & 0.000744 & $-4.26 e-05$ & $0.000763^{*}$ & -0.000131 \\
\hline & $(0.000519)$ & $(0.000632)$ & $(0.000367)$ & $(0.000447)$ & $(0.000453)$ \\
\hline \multirow[t]{2}{*}{ Household size } & 0.00118 & 0.000650 & 0.00190 & $0.00614^{* *}$ & 0.00101 \\
\hline & $(0.00261)$ & $(0.00185)$ & $(0.00258)$ & $(0.00248)$ & $(0.00224)$ \\
\hline \multirow[t]{2}{*}{ Medium town } & 0.00191 & -0.00220 & -0.0157 & $0.0262^{* * *}$ & $0.0121^{* *}$ \\
\hline & $(0.0101)$ & $(0.0115)$ & $(0.00862)$ & $(0.0101)$ & $(0.00619)$ \\
\hline \multirow[t]{2}{*}{ Large town/city } & 0.00134 & 0.0261 & -0.00361 & 0.00684 & $0.0207^{*}$ \\
\hline & $(0.00895)$ & $(0.0206)$ & $(0.0117)$ & $(0.00726)$ & $(0.0124)$ \\
\hline \multirow[t]{2}{*}{ Constant } & $0.668^{* * *}$ & $0.656^{* * *}$ & $0.806^{* * *}$ & $0.763^{* * *}$ & $0.740^{* * *}$ \\
\hline & $(0.0208)$ & (0.0199) & $(0.0152)$ & $(0.0310)$ & $(0.0238)$ \\
\hline Observations & 28,583 & 28,583 & 28,583 & 28,583 & 28,583 \\
\hline $\begin{array}{l}\text { Wooldridge } \\
\text { exog. F }\end{array}$ & 11.10 & 4.80 & 11.53 & 6.22 & 0.621 \\
\hline ( $p$-value) & $(0.0027)$ & $(0.038)$ & $(0.0023)$ & $(0.0196)$ & $(0.438)$ \\
\hline
\end{tabular}

Robust standard errors in parentheses are clustered at the country level. Probability weights supplied by Eurobarometer used in all regressions. All regressions include NUTS Region FE and Survey Year FE.

$*_{p}<0.1$.

$* * p<0.05$.

$* * * p<0.01$.

The final question we examine is, "In your opinion, to what extent do the following factors influence your "quality of life'?" The three factors on the survey are "state of the environment," "economic factors," and "social factors." Respondents have the options of answering with "very much," "quite a lot," "not much," "not at all," or "don't know." We group "very much" and "quite a lot" together as "yes" and "not much" and "not at all" together as "no." Then, we estimate a linear probability model using 2 SLS to see how individual unemployment affects the answer to this question. In Columns 3 and 4 of Table 8, we see a negative sign on unemployment for the state of the environment and a positive sign on unemployment for economic factors. This provides further evidence that it may be the cost saving potential of certain PEB's that is largely motivating unemployed individuals. The importance of social factors serves as a validity check. A negative sign here could signify that individuals simply care 
less about all kinds of things when they become unemployed, calling into question the importance of the finding for the state of the environment. A positive sign could similarly call into question the importance of the result on economic factors. However, as shown in Column 5 of Table 8 , the estimated coefficient on individual unemployment is close to 0 and highly statistically insignificant, suggesting that unemployment does not cause any change to how individuals perceive the importance of social factors.

\section{Conclusion}

We use a new approach in this paper to identify the causal impact of individual level unemployment on PEB. Unemployed individuals are likely different on average from employed individuals in unobservable ways. Thus, we adopt an instrumental variables approach to deal with potential endogeneity. This is important because, from a policy perspective, we would be more interested in what happens to PEB when one becomes unemployed than describing how unemployed individuals are observationally different from employed individuals. We may also be able to draw more general insights into what causes PEB to increase or decrease by examining how different PEB's that require different inputs change due to unemployment.

Unemployment causes income to fall and hence decreases the opportunity cost of an individual's time. Drawing on the private provision of public goods literature, we formulate hypotheses that unemployment will increase PEB's that mainly require effort/time as inputs and decrease PEB's that mainly require monetary contributions. Utilizing an EU-27 population representative sample, we find empirical evidence to support these hypotheses. Thus, it appears that unemployment is not good for environmental initiatives that require monetary contributions and good for environmental initiatives that mainly require time/effort or deliver potential cost savings.

To supplement our main analysis, we examine several other questions on the Eurobarometer surveys to see how unemployment affects the importance of environmental issues in the lives of respondents. Here, we find strong evidence that unemployment leads individuals to perceive environmental issues as playing a smaller role in their quality of life and to have a lower direct daily effect on their lives. Furthermore, unemployment causes individuals to perceive economic issues as playing a larger role in their quality of life and to be significantly less likely to say that they would buy green products that have higher cost.

Our results have important implications for policy interventions that hope to increase the extent of PEB. When individuals' incomes fall due to unemployment, we expect them to shift away from PEB's that require monetary contributions and toward PEB's that may deliver cost savings and that require mainly time/effort as inputs. Therefore, to increase PEB's on the net during periods of high 
unemployment, policymakers and environmental interest groups may be wise to emphasize the cost savings of the behaviors as opposed to appealing to the social environmental benefits. Furthermore, this reinforces the importance of creating a system of personal financial incentives for PEB's that we wish to encourage. For example, reducing the usage of disposables provides environmental benefits to society. However, at the margin, there are typically not cost savings associated with reducing garbage output. This bears out in our results where we see no reduction in disposables due to unemployment. A system that rewarded marginal reductions in garbage output could potentially be influential during periods of increased unemployment when more individuals are actively searching for cost saving behaviors.

Finally, our key identifying assumption is that within-region shocks to unemployment affect the probability of an individual being unemployed but do not directly affect PEB. We utilize pooled crosssections of individuals so we only observe a given individual one time. A next step in analyzing the effect of unemployment on PEB would be to leverage panel data. If one could identify a data source that tracks individuals over time and asks questions about their PEB, one could then control for timeinvariant factors that may be correlated with both individual unemployment and PEB.

\section{References}

Andreoni, 1988. J. Andreoni. Privately provided public goods in a large economy: the limits of altruism. J. Public Econ., 35 (1) (1988), pp. 57-73

Andreoni, 1990. J. Andreoni. Impure altruism and donations to public foods: a theory of warm-glow giving. Econ. J., 100 (401) (1990), pp. 464-477

Andreoni and Levinson, 2001. J. Andreoni, A. Levinson. The simple analytics of the environmental Kuznets curve. J. Public Econ., 80 (2) (2001), pp. 269-286

Angrist and Pischke, 2009. J.D. Angrist, J. Pischke. Mostly Harmless Econometrics: An Empiricist's Companion. Princeton University Press, Princeton and Oxford (2009)

Bergstrom et al., 1986. T. Bergstrom, L. Blume, H. Varian. On the private provision of public goods. J. Public Econ., 29 (1) (1986), pp. 25-49

Brecard et al., 2009. D. Brecard, B. Hlaimi, S. Lucas, Y. Perraudeau, F. Salladarre. Determinants of demand for green products: an application to eco-label demand for fish in Europe. Ecol. Econ., 69 (1) (2009), pp. 115-125

Brekke et al., 2003. K.A. Brekke, S. Kverndokk, K. Nyborg. An economic model of moral motivation. J. Public Econ., 87 (9-10) (2003), pp. 1967-1983

Bulte et al., 2005. E. Bulte, S. Gerking, J.A. List, A. de Zeeuw. The effect of varying the causes of environmental problems on stated WTP values: evidence from a field study. J. Environ. Econ. Manage., 49 (2) (2005), pp. 330-342

Carson, 2010. R.T. Carson. The environmental Kuznets curve: seeking empirical regularity and theoretical structure. Rev. Environ. Econ. Policy, 4 (1) (2010), pp. 3-23 
Chi and Drewianka, 2014. M. Chi, S. Drewianka. How much is a green card worth? Evidence from Mexican men who marry women born in the U.S. Labour Econ., 31 (0) (2014), pp. 103-116

Clark et al., 2003. C.F. Clark, M.J. Kotchen, M.R. Moore. Internal and external influences on pro-environmental behavior: participation in a green electricity program. J. Environ. Psychol., 23 (3) (2003), pp. 237-246

De Silva and Pownall, 2014. D.G. De Silva, R.A.J. Pownall. Going green: does it depend on education, gender or income? Appl. Econ., 46 (5) (2014), pp. 573-586

Dietz et al., 2002. T. Dietz, L. Kalof, P.C. Stern. Gender, values, and environmentalism. Soc. Sci. Q., 83 (1) (2002), pp. 353-364

Eisler et al., 2003. A.D. Eisler, H. Eisler, M. Yoshida. Perception of human ecology: cross-cultural and gender comparisons. J. Environ. Psychol., 23 (1) (2003), pp. 89-101

European Commission, 2012. European Commission. Eurobarometer 68.2 (Nov-Dec 2007). TNS Opinion \& Social, Brussels [Producer]. GESIS Data Archive, Cologne. ZA4742 Data File Version 4.0.1. (2012), 10.4232/1.10986

European Commission, 2014a. European Commission. Eurobarometer 75.2 (2011). TNS Opinion \& Social, Brussels [Producer]. GESIS Data Archive, Cologne. ZA5480 Data File Version 4.0.1. (2014), 10.4232/1.11853

European Commission, 2014b. European Commission. Eurobarometer 75.2-Variable Report. Documentation of the Archive Release. Dataset Version 4.0.1. GESIS Study No. ZA5480. (2014), 10.4232/1.11853

Eurostat, 2014. Eurostat, 2014.

Available: http://epp.eurostat.ec.europa.eu/portal/page/portal/statistics/search database(accessed 01.08.14.).

Ferreira and Moro, 2013. S. Ferreira, M. Moro. Income and preferences for the environment: evidence from subjective well-being data. Environ. Plan. A, 45 (3) (2013), pp. 650-667

Fidrmuc and Gërxhani, 2005. J. Fidrmuc, K. Gërxhani. Formation of Social Capital in Central and Eastern Europe: Understanding the Gap vis-a-vis Developed Countries, William Davidson Institute Working Paper No. 766. SSRN (2005). Available at: http://ssrn.com/abstract=729324

Harbaugh, 1998. W.T. Harbaugh. What do donations buy? A model of philanthropy based on prestige and warm glow. J. Public Econ., 67 (2) (1998), pp. 269-284

Heckman, 1978. J.J. Heckman. Dummy endogenous variables in a simultaneous equation system. Econometrica, 46 (4) (1978), pp. 931-959

Holländer, 1990. H. Holländer. A social exchange approach to voluntary cooperation. Am. Econ. Rev., 80 (5) (1990), pp. 1157-1167

Hunter et al., 2004. L.M. Hunter, A. Hatch, A. Johnson. Cross-national gender variation in environmental behaviors. Soc. Sci. Q., 85 (3) (2004), pp. 677-694

Johnson et al., 2004. C.Y. Johnson, J.M. Bowker, H.K. Cordell. Ethnic variation in environmental belief and behavior: an examination of the new ecological paradigm in a social psychological context. Environ. Behav., 36 (2) (2004), pp. 157-186

Kahn, 1998. M.E. Kahn. A household level environmental Kuznets curve. Econ. Lett., 59 (2) (1998), pp. 269-273 
Kahn and Kotchen, 2011. M.E. Kahn, M.J. Kotchen. Business cycle effects on concern about climate change: the chilling effect of recession. Clim. Change Econ., 02 (03) (2011), pp. 257-273

Martinez and McMullin, 2004. T. Martinez, S. McMullin. Factors affecting decisions to volunteer in nongovernmental organizations. Environ. Behav., 36 (1) (2004), pp. 112-126

Newey, 1990. W.K. Newey. Efficient instrumental variables estimation of nonlinear models. Econometrica, 58 (4) (1990), pp. 809-837

Nomenclature of Territorial Units for Statistics, 2014. Nomenclature of Territorial Units for Statistics, 2014.

Eurostat. Available at: http://ec.europa.eu/eurostat/web/nuts/overview.

Olson, 1965. M. Olson. The Logic of Collective Action. Harvard University Press, Cambridge, MA (1965)

Papacostas, 2012. A. Papacostas. Eurobarometer 68.2-Variable Report. Documentation of the Archive

Release. Dataset Version 4.0.1. GESIS Study No. ZA4742. (2012), 10.4232/1.10986

Popp, 2001. D. Popp. Altruism and the demand for environmental quality. Land Econ., 77 (3) (2001), pp. 339349

Rege, 2004. M. Rege. Social norms and private provision of public goods. J. Public Econ. Theory, 6 (1) (2004), pp. 65-77

Ruhm, 2000. C.J. Ruhm. Are recessions good for your health? Q. J. Econ., 115 (2) (2000), pp. 617-650

Stock et al., 2002. J.H. Stock, J.H. Wright, M. Yogo. A survey of weak instruments and weak identification in feneralized method of moments. J. Bus. Econ. Stat., 20 (4) (2002), pp. 518-529

Torgler and García-Valiñas, 2007. B. Torgler, M.A. García-Valiñas. The determinants of individuals' attitudes towards preventing environmental damage. Ecol. Econ., 63 (2-3) (2007), pp. 536-552

Torgler et al., 2010. B. Torgler, M.A. García-Valiñas, A. Macintyre. Participation in Environmental Organizations. Routledge, New York, NY (2010)

Torgler et al., 2011. B. Torgler, M.A. García-Valiñas, A. Macintyre. Participation in environmental organizations: an empirical analysis. Environ. Dev. Econ., 16 (5) (2011), pp. 591-620

Torgler et al., 2012. B. Torgler, M.A. García-Valiñas, A. Macintyre. Justifiability of littering: an empirical investigation. Environ. Values, 21 (2) (2012), pp. 209-231

Turaga et al., 2010. R.M.R. Turaga, R.B. Howarth, M.E. Borsuk. Pro-environmental behavior. Ann. N. Y. Acad. Sci., 1185 (1) (2010), pp. 211-224

Veisten et al., 2004. K. Veisten, H. Fredrik Hoen, S. Navrud, J. Strand. Scope insensitivity in contingent valuation of complex environmental amenities. J. Environ. Manage., 73 (4) (2004), pp. 317-331

Whitehead, 1991. J.C. Whitehead. Environmental interest group behavior and self-selection bias in contingent valuation mail surveys. Growth Change, 22 (1) (1991), pp. 10-20

Witzke and Urfei, 2001. H.P. Witzke, G. Urfei. Willingness to pay for environmental protection in Germany: coping with the regional dimension. Reg. Stud., 35 (3) (2001), pp. 207-214

Zelezny et al., 2000. L.C. Zelezny, P. Chua, C. Aldrich. New ways of thinking about environmentalism: elaborating on gender differences in environmentalism. J. Soc. Issues, 56 (3) (2000), pp. 443-457

${ }^{1}$ Nomenclature of Territorial Units for Statistics (NUTS) is the Eurostat hierarchical system for dividing up the economic territory of the EU (Nomenclature of Territorial Units for Statistics, 2014). 
${ }^{2}$ The range of the magnitude of the LATE (local average treatment effect), representing the average change in the probability of a complier performing the behavior within the last month, is given in parentheses. 3http://www.gesis.org/en/eurobarometer/data-access/.

${ }^{4}$ Throughout the paper, any reference to NUTS regions corresponds to these NUTS groupings.

${ }^{5}$ As a practical concern, including additional employment categories would require additional instrumental variables to identify a causal effect.

$\underline{6}$ Brekke et al. (2003) is focused on applications related to behaviors that are effort/time consuming so the model does not consider monetary contributions to the public good. One could also imagine a model where financial contributions to a public good lead to improved self-image.

${ }^{7}$ Note that we should only be including exogenous variables that can be thought of as pre-determined to the natural experiment at hand. Therefore, variables that can be considered outcomes of unemployment or simultaneously determined with unemployment should not be included in the regression.

${ }^{8}$ With more than one IV, one can conduct a test of overidentifying restrictions. However, this test is not necessarily informative when there is treatment effect heterogeneity (Angrist and Pischke, 2009).

9 One other argument in favor of the instrumental variable is that estimates of $\beta$ do not change much at all when omitting the controls of gender, age, household size, and whether the individual lives in a rural area, a medium-sized town, or a large town/city. This suggests that the instrument is approximately randomly assigned. These results are available upon request.

${ }^{10}$ Specifications including the potentially endogenous controls of education, political affiliation, and marital status were also estimated using 2SLS. The signs on the coefficient of unemployment status are unchanged across the 8 PEB's (with the exception of environmental friendly transportation which is close to 0). Moreover, coefficients that are statistically significant in Tables 3-6 remain significant. These results are available upon request.

${ }^{11}$ We also estimate a probit model for each of the 8 PEB's. The average estimated marginal effects from the probit model are nearly identical to the corresponding linear probability estimates.

$\underline{12}$ Limited information maximum likelihood has been shown to produce less bias in finite samples. We alternatively utilize this method with very similar results to those presented.

${ }^{13}$ Alternatively, we add a second IV to the model (\% of early leavers from education). These results are similar to the just-identified results presented in the paper. All of the results from these alternative models are presented in the working paper version of this manuscript at SSRN.

14 This approach was proposed by Heckman (1978) and generalized by Newey (1990).

${ }^{15}$ We also run the reduced-form regressions of environmental behaviors on the excluded instrument and covariates. T-stats on excluded instruments in these regressions are statistically significant and of the correct sign, providing further evidence of a causal relation. These results are available upon request.

${ }^{16}$ Results for the traditional IV approach are similar in spirit, with estimated coefficients that are approximately $50 \%$ larger in absolute value than those presented here. 
